\title{
On the Role of Menaquinone-6 in the Electron Transport of Hydrogen:Fumarate Reductase System in the Strict Anaerobe Desulfovibrio gigas
}

\author{
By E. C. HATCHIKIAN \\ Laboratoire de Chimie Bactérienne, C.N.R.S., \\ 31, chemin J.-Aiguier, 13274 Marseille Cedex 2, France \\ (Received I3 July I973; revised I September 1973)
}

INTRODUCTION

The genus Desulfovibrio includes a great number of micro-organisms exhibiting a strictly anaerobic mode of growth based on reduction of sulphate as terminal electron acceptor (Postgate, 1965). Several species including Desulfovibrio gigas grow in a sulphate-free medium in the presence of fumarate (Miller \& Wakerley, 1966). The enzymes allowing fumarate dismutation into acetate and succinate were studied in D. gigas (Hatchikian \& Le Gall, $1970 a, b)$ and an increased level of fumarate reductase activity was observed in the particulate fraction prepared from $D$. gigas grown on fumarate or fumarate-sulphate medium compared with that from cells cultivated on lactate-sulphate (Hatchikian \& Le Gall, 1972). The particulate $\mathrm{H}_{2}$ : fumarate reductase system contains hydrogenase coupled with fumarate reductase by one or more intermediary electron carriers replaceable by viologen dyes. The presence of a particulate $b$-type cytochrome in $D$. gigas and its role in the reduction of fumarate by molecular hydrogen has already been reported (Hatchikian \& Le Gall, 1972), but the role in the electron transport system of membrane-bound menaquinone-6 isolated from this microorganism (Maroc, Azerad, Kamen \& Le Gall, 1970; Weber, Matschiner \& Peck, 1970) has not been established. In this paper we report the possible participation of menaquinone- 6 in the electron transport from hydrogen to fumarate in D. gigas particles.

\section{METHODS}

Organism, growth and preparation of particles. Desulfovibrio gigas NCIB9332 was grown at $37^{\circ} \mathrm{C}$ on various media: lactate-sulphate (Le Gall, Mazza \& Dragoni, I965), fumaratesulphate and fumarate (Miller \& Wakerley, 1966). Methods of preparing extract as well as particulate and soluble fractions have already been described (Hatchikian \& Le Gall, 1970a).

Preparation of quinone-depleted particles. Quinone-depleted particles were prepared by extraction with a mixture of acetone and water as described for mitochondria by Lester \& Fleischer (196I).

Irradiated particles. Ultraviolet irradiation was used to destroy menaquinone-6 (MK-6) present in the particles; this treatment was performed as follows: an original Hanau Q 8I lamp ( $350 \mathrm{~W}$; maximum emission $360 \mathrm{~nm}$ ) was plunged into $500 \mathrm{ml}$ of a vigorously stirred suspension of particles ( $1.5 \mathrm{mg}$ protein $/ \mathrm{ml}$ ) in $0.025 \mathrm{M}$-tris- $\mathrm{HCl}$ buffer $(\mathrm{pH} 7.6)$ for $6 \mathrm{~min}$ irradiation at $4{ }^{\circ} \mathrm{C}$. The treated suspension was then centrifuged at $65000 \mathrm{~g}$ in a Spinco centrifuge (rotor 30 ) for $30 \mathrm{~min}$ and the residue was suspended in the same buffer at a concentration of $20 \mathrm{mg} / \mathrm{ml}$. For spectroscopy, lyophilized irradiated (or unirradiated) particles corresponding to $200 \mathrm{mg}$ protein were suspended in $2 \mathrm{ml}$ of pentane and extracted by gentle 
stirring at $4{ }^{\circ} \mathrm{C}$ for $5 \mathrm{~min}$. After centrifuging at $30000 \mathrm{~g}$ for $5 \mathrm{~min}$, the supernatant was diluted with an equal volume of $n$-pentane and the u.v. absorption spectrum determined in cuvettes with I cm light path.

Restoration studies. Restoration of the coupled $\mathrm{H}_{2}$ : fumarate reductase activity was attempted in two ways: (i) MK-6 (or menadione) in ethanolic solution was added to the extracted or irradiated particles $(0.05 \mathrm{mg} / \mathrm{mg}$ protein) and the suspension was incubated for $\mathrm{I} \mathrm{h}$ at room temperature with gentle stirring, (ii) MK-6 suspended in Desulfovibrio gigas phospholipids was added to the treated particles; phospholipids extracted from whole cells were prepared by the method of Kanemasa, Akamatsu \& Nojima (I967). Phospholipids (I60 mg) were homogenized by sonic oscillation in a Sonifier S I Io oscillator for I min periods in $5 \mathrm{ml}$ of buffer containing $0.25 \mathrm{M}$-sucrose, I mM-EDTA and $0.0 \mathrm{O} \mathrm{M}$-tris- $\mathrm{HCl}(\mathrm{pH} 7 \cdot 6)$. After centrifuging the suspension at $35000 \mathrm{~g}$ for $15 \mathrm{~min}, \mathrm{MK}-6$ ( $2 \mathrm{mg}$ of menaquinone in a minimum amount of ethanol) was added to the supernatant and sonicated for three $10 \mathrm{~s}$ intervals at 0 to $5{ }^{\circ} \mathrm{C}$, whereupon a colloidal suspension was formed. This suspension was then incubated with the extracted or irradiated particles for $\mathrm{I} h$ at room temperature; the amounts used in the mixture were $0.1 \mathrm{ml}$ of the phospholipid suspension/mg of particulate protein.

Preparation of menaquinone-depleted phospholipids. D. gigas phopholipid free from natural MK-6 was prepared as follows: a sample of phospholipid (300 mg) was dissolved in chloroform and loaded on a column of silicic acid ( $10 \times 50 \mathrm{~mm})$ packed with chloroform; the column was washed with chloroform to remove MK-6; the phospholipids were then eluted with a mixture of chloroform and methanol (I:I, v/v) and dried under vacuum below $25^{\circ} \mathrm{C}$.

Measurement of $\mathrm{H}_{2}$ : fumarate reductase activity. The $\mathrm{H}_{2}$ : fumarate reductase activity of the particulate fraction was determined using the Warburg respirometric method. Initial rates of $\mathrm{H}_{2}$ uptake during fumarate reduction were measured in the presence of an excess of hydrogenase, and for this purpose a hydrogenase fraction devoid of fumarate reductase activity prepared as already described (Hatchikian \& Le Gall, 1972) was added to the particulate fraction. The unit of hydrogenase activity was defined as $\mu \mathrm{mol} \mathrm{H}_{2}$ oxidized/h with the manometric benzyl viologen assay. The assay conditions for the measurement of $\mathrm{H}_{2}$ : fumarate reductase activity were as follows. Main compartment: tris- $\mathrm{HCl}$ buffer $\left(\mathrm{pH}_{7} \cdot 6\right)$, I $00 \mu \mathrm{mol}$; hydrogenase, I05 units; methyl viologen (MV) where indicated, $7.5 \mu \mathrm{mol}$; enzyme, as indicated. Side-arm: fumarate, $25 \mu \mathrm{mol}$. Centre well : $0.05 \mathrm{ml} 20 \% \mathrm{NaOH}$. Total volume, $3 \mathrm{ml}$; temperature, $37^{\circ} \mathrm{C}$; gas phase, $\mathrm{H}_{2}$.

Analytical methods. Dicarboxylic acids present in the reaction mixture were identified by descending chromatography on Whatman no. I paper as described by Miller \& Wakerley (1966). The phospholipids were assayed after digestion by estimation of the phosphorus content by the method of Fiske \& SubbaRow (1925). Protein was estimated by the biuret method (Gornall, Bardawill \& David, 1949) and by the method of Lowry, Rosebrough, Farr \& Randall (195I).

\section{RESULTS}

\section{Effects of extraction and reincorporation of menaquinone}

Acetone-extraction of the particles resulted in the loss of $\mathrm{H}_{2}$ : fumarate reductase activity but with MV the extracted particles regained about $60 \%$ activity. In a typical experiment, a particulate fraction of fumarate-grown Desulfovibrio gigas (I.9 mg protein) absorbed I9.5 $\mu$ mol $\mathrm{H}_{2} / \mathrm{h}$, which increased to $75 \mu \mathrm{mol} \mathrm{H}_{2} / \mathrm{h}$ with $2.5 \mathrm{mM}-\mathrm{MV}$; acetone-extracted particles were inactive but absorbed $45 \cdot 2 \mu \mathrm{mol} \mathrm{H}_{2} / \mathrm{h}$ with $\mathrm{MV}$. Comparable results were obtained with 
particles from lactate-grown D. gigas. MV probably couples hydrogenase to fumarate reductase directly, and in the presence of excess hydrogenase the assay simply measures the fumarate reductase activity of the particles. These results suggest that washing the particles with acetone eliminates a lipid-soluble factor involved in the electron transport between hydrogenase and fumarate reductase. A yellow lipid fraction was obtained from the acetone extract by evaporating the solvent, and its u.v. absorption spectrum indicated that a quinone was present. Addition of this fraction or of MK-6 (with or without D. gigas phospholipids) failed to restore $\mathrm{H}_{2}$ : fumarate reductase activity.

\section{Effect of electron transport inhibitors on $\mathrm{H}_{2}$ : fumarate reductase activity}

Dicoumarol and lapachol were tested on the $\mathrm{H}_{2}$ : fumarate reductase activity of the particles from $D$. gigas grown on fumarate medium. The addition of dicoumarol $\left(5 \times \mathrm{IO}^{-4} \mathrm{M}\right)$ to a system containing $\mathrm{I} \cdot 4 \mathrm{mg}$ protein produced a $50 \%$ inhibition, whereas lapachol had no inhibitory effect at low concentrations $\left(<\mathrm{IO}^{-4} \mathrm{M}\right)$ and a stimulatory effect at high concentrations $\left(>1 \mathrm{IO}^{-4} \mathrm{M}\right)$.

\section{Effect of ultraviolet irradiation on particles}

Irradiation of the particles resulted in a considerable loss of $\mathrm{H}_{2}$ : fumarate reductase activity but in the presence of MV the preparations retained $60 \%$ of the activity of unirradiated intact particles with methyl viologen. These results implicate a light-sensitive factor, possibly MK-6, in the electron transport of the particulate $\mathrm{H}_{2}$ : fumarate reductase activity.

To investigate whether the endogenous MK-6 was altered by the irradiation procedure, the u.v. spectra of pentane extracts from normal and irradiated particles were compared. The spectrum from the extract of unirradiated particles has absorption maxima corresponding to that of the spectrum of MK-6 described by Weber et al. (I970). The disappearance of these peaks in the spectrum of the extract of irradiated particles indicated the destruction of the naphthoquinone ring (Brodie \& Ballantine, 1960).

Restoration experiments by reincorporation of MK-6 in the irradiated particles were carried out to determine whether the loss of $\mathrm{H}_{2}$ : fumarate reductase activity was due to the alteration of endogenous MK-6. The results of these experiments are presented in Fig. I. After addition of MK-6 or menadione, the coupled activity was partly restored; moreover, the restoration was slightly more efficient in the presence of MK-6 plus Desulfovibrio gigas phospholipids. Under these conditions, the $\mathrm{H}_{2}$ : fumarate reductase activity was restored to a maximum of $\mathrm{I} 7 \%$ of the activity of unirradiated particles, i.e. about three times the residual activity of the irradiated particles. The activity observed with phospholipids alone (Fig. I E) was probably due to the presence of menaquinone in the crude preparation. In support of this, the absorption spectrum of the phospholipids indicated that menaquinone was present and the addition of D. gigas phospholipids free from MK-6 to the irradiated particles failed partly to restore $\mathrm{H}_{2}$ : fumarate reductase activity (Fig. I G). Furthermore, preincubation of the irradiated particles with pure phospholipids such as phosphatidyl-ethanolamine ( $10 \mu \mathrm{g} / 3 \mathrm{ml}$ of assay system, dissolved in ethanol) from bacteria (Calbiochem Ltd., Los Angeles, California, U.S.A.) or cardiolipin from bovine heart (Sigma Chemical Co., St Louis, Missouri, U.S.A.) did not increase the enzymic activity. The restored activity appeared to be physiological in that it was inhibited by 2 -heptyl-4-hydroxyquinoline- $N$-oxide (Fig. I H) like the $\mathrm{H}_{2}$ :fumarate reductase activity of the untreated particles (Hatchikian \& Le Gall, 1972). The formation of succinate was confirmed in the systems in which the activity of irradiated particles was partly restored by reincorporation of MK-6. 


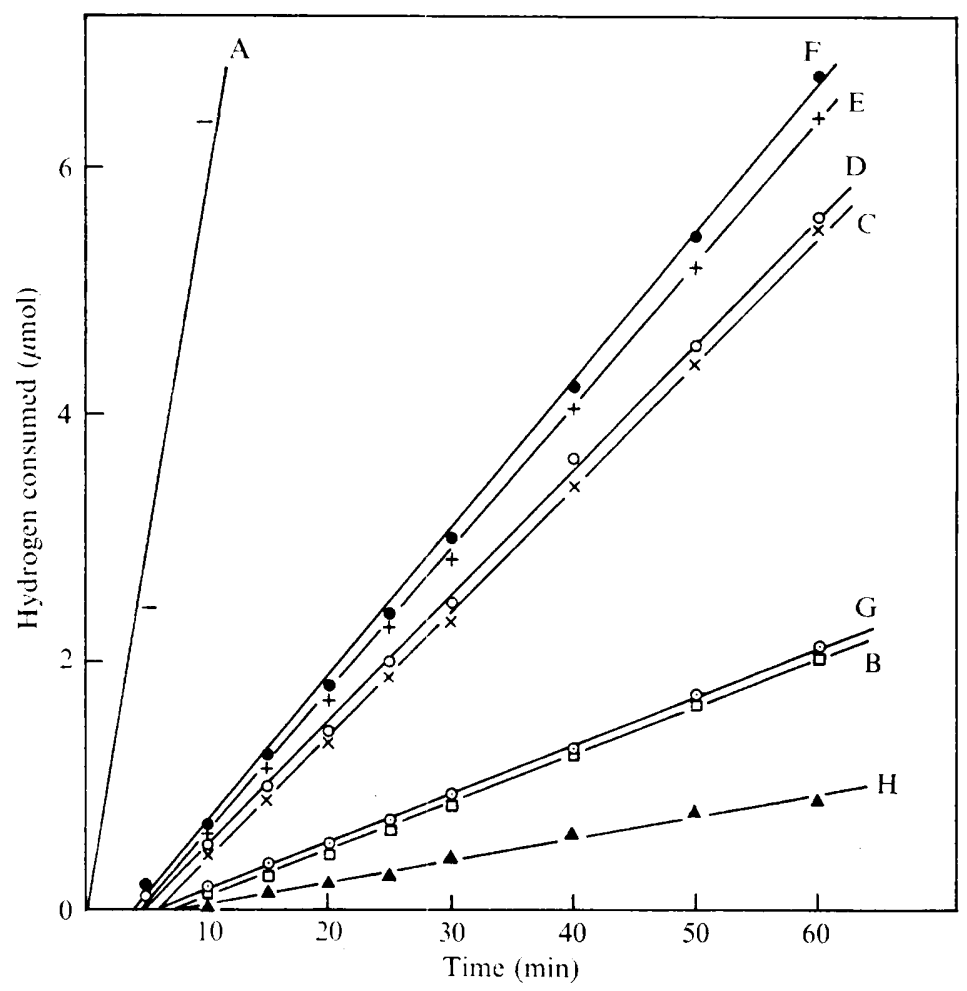

Fig. I. Restoration by menaquinone- 6 of the $\mathrm{H}_{2}$ : fumarate reductase activity in irradiated particles of Desulfovibrio gigas. The reaction mixture contained all the reactants as indicated in Methods. A, unirradiated particles from D. gigas grown on fumarate, protein content $3.3 \mathrm{mg}$. The other systems contained irradiated particles, protein content $3.2 \mathrm{mg}$. B, irradiated particles alone; $\mathrm{C}$, with MK-6 (0.15 mg); D, with menadione (0.15 mg); E, with D. gigas phospholipids; F, with MK-6 $+D$. gigas phospholipids; $\mathrm{G}, D$. gigas phospholipids purified on silicic acid column; $\mathrm{H}$, with MK-6 + phospholipids + 2-heptyl-4-hydroxyquinoline- $N$-oxide $\left(\mathrm{IO}^{-5} \mathrm{M}\right)$. The phospholidid content in the systems containing these compounds corresponded to $20 \mu \mathrm{g}$ of phosphorus.

\section{DISCUSSION}

The strict anaerobe Desulfovibrio gigas has recently been found to contain MK-6 (Maroc et al. 1970; Weber et al. 1970). The data presented show that when MK-6 is removed from particles by extraction with acetone or destroyed by u.v. irradiation a concomitant loss of $\mathrm{H}_{2}$ : fumarate reductase activity is observed. In both cases fumarate reductase activity can still be detected using MV as an artificial coupling factor. Electron transport from $\mathrm{H}_{2}$ to fumarate is inhibited by dicoumarol, a menaquinone antagonist. However, incubation of treated particles with menaquinone either failed to restore activity (acetone-extracted particles) or only partly restored $\mathrm{H}_{2}$ : fumarate reductase activity (u.v.-irradiated particles). These experiments also suggested that phospholipids slightly enhanced the restoration of the activity obtained with MK-6, possibly by improving the reincorporation of MK-6 at its site of action in the particle. If we consider that fumarate reductase is inactivated to $40 \%$ by u.v. light as indicated by the results reported here, the level of restoration of the $\mathrm{H}_{2}$ : fumarate reductase activity by addition of MK-6 to irradiated particles may actually be higher than that mentioned above and can be estimated to be close to $25 \%$. 
The data discussed above strongly suggest that MK-6 is involved in the electron transport between hydrogenase and fumarate reductase in Desulfovibrio gigas particles. Similar results, corresponding to a partial restoration of enzymic activities by quinone reincorporation into extracts depleted of these carriers, have already been reported (Knook \& Planta, 1971; Kröger \& Dadak, 1969). However, in the case of NADH oxidase activity of Bacillus brevis, no restoration was observed upon addition of the natural quinone (Fynn, Thomas \& Seddon, 1972). The low level of restoration of $\mathrm{H}_{2}$ : fumarate reductase activity of u.v.-irradiated $D$. gigas particles may be due to failure of the techniques used to place MK-6 back to its original site in the particle (Fynn et al. 1972). In particular, the presence of altered endogenous menaquinone in irradiated $D$. gigas-particles could prevent reincorporation of exogenously added quinone (Knook \& Planta, 1971).

The role of menaquinones in electron transport coupled with fumarate reductase has already been reported in Bacillus megaterium (Kröger \& Dadak, 1969) and Proteus rettgeri (Kröger, Dadak, Klingenberg \& Diemer, I97I). Kröger \& Dadak (1969) showed that in B. megaterium, menaquinone-7 mediates the electron flow between the dehydrogenases (NADH-, malate- or glycerol-I-P-dehydrogenase) and a cytochrome $b_{1}$ linked to fumarate reductase. The involvement of Desulfovibrio gigas membrane-bound cytochrome $b$, now called cytochrome $B_{560}$ (Hatchikian, 1972), in the electron transport of the $\mathrm{H}_{2}$ : fumarate reductase system (Hatchikian \& Le Gall, I972) and the possible participation of MK-6 in this electron transport chain, as reported here, suggest that both MK- 6 and cytochrome $B_{560}$ are needed to couple hydrogenase and fumarate reductase.

The author thanks Mrs N. Forget for excellent technical assistance. The u.v.-irradiation experiments reported in this paper were carried out in the Laboratoire de Chimie Organique Appliquée, Université de Provence, France, with the helpful assistance of Dr E. Ucciani. The author thanks Dr J. Le Gall for many valuable suggestions throughout this work, Dr O. Isler for a gift of menaquinone-6 and Dr L. Fieser for a gift of lapachol.

\section{REFERENCES}

Brodie, A. F. \& Ballantine, J. (1960). Oxidative phosphorylation in fractionated bacterial systems. II. The role of vitamin K. Journal of Biological Chemistry 235, 226-23I.

FISKE, C. H. \& SubbaRow, Y. (1925). The colorimetric determination of phosphorus. Journal of Biological Chemistry 66, 375-400.

FynN, G. H., Thomas, D. V. \& Seddon, B. (1972). On the role of menaquinone in the reduced nicotinamide adenine dinucleotide oxidative pathway of Bacillus brevis. Journal of General Microbiology 70, 27I-275.

Gornall, A. G., Bardawill, G. J. \& David, M. M. (1949). Determination of serum proteins by means of the biuret reaction. Journal of Biological Chemistry $\mathbf{1 7 7}, 75 \mathrm{I}-766$.

Hatchikian, E. C. (1972). Mécanismes d'oxydo-réduction chez les bactéries sulfato-réductrices. Thèse de Doctorat ès-Sciences. Université d'Aix-Marseille II, France.

Hatchikian, E. C. \& Le Gall, J.(I970a). Étude du métabolisme des acides dicarboxyliques et du pyruvate chez les bactéries sulfato-réductrices. I. Étude du l'oxydation enzymatique du fumarate en acétate. Annales de l'Institut Pasteur 118, I25-142.

Hatchikian, E. C. \& Le Gall, J. (1970b). Étude de métabolisme des acides dicarboxyliques et du pyruvate chez les bactéries sulfato-réductrices. II. Transport des electrons; accepteurs finaux. Annales de l'Institut Pasteur 118, 288-301.

Hatchikian, E. C. \& LE Gall, J. (I972). Evidence for the presence of a $b$-type cytochrome in the sulfatereducing bacterium Desulfovibrio gigas, and its role in the reduction of fumarate by molecular hydrogen. Biochimica et biophysica acta 267, 479-484.

Kanemasa, Y., Akamatsu, Y. \& Nojima, S. (1967). Composition and turnover of the phospholipids in Escherichia coli. Biochimica et biophysica acta I44, 382-390. 
KNook, D. L. \& Planta, R. J. (197I). Function of ubiquinone in electron transport from reduced nicotinamide adenine dinucleotide to nitrate and oxygen in Aerobacter aerogenes. Journal of Bacteriology 105, 483-488.

KRöger, A. \& DADAK, V. (1969). On the role of quinones in bacterial electron transport; the respiratory system of Bacillus megaterium. European Journal of Biochemistry II, 328-340.

Kröger, A., Dadak, V., KLINGenberg, M. \& Diemer, F. (1971). On the role of quinones in bacterial electron transport; differential roles of ubiquinone and menaquinone in Proteus rettgeri. European Journal of Biochemistry 21, 322-333.

Le Gall, J., Mazza, G. \& Dragoni, N. (1965). Le cytochrome $c_{3}$ de Desulfovibrio gigas. Biochimica et biophysica acta 99, 385-387.

Lester, R. L. \& Fleischer, S. (I96I). Studies on the electron-transport system. XXVII. The respiratory activity of acetone-extracted beef-heart mitochondria role of coenzyme $Q$ and other lipids. Biochimica et biophysica acta 47, 358-377.

Lowry, D. H., Rosebrough, N. J., Farr, A. L. \& Randall, R. J. (195I). Protein measurement with the Folin phenol reagent. Journal of Biological Chemistry 193, 265-275.

Maroc, J., Azerad, R., Kamen, M. D. \& Le Gall, J. (I970). Menaquinone (MK-6) in the sulfate-reducing obligate anaerobe, Desulfovibrio. Biochimica et biophysica acta 197, 87-89.

MiLleR, J. D. A. \& WAKERLEY, D. S. (1966). Growth of sulphate-reducing bacteria by fumarate dismutation. Journal of General Microbiology 43, I0I-I07.

Postgate, J. R. (1965). Recent advances in the study of the sulfate-reducing bacteria. Bacteriological Reviews 29, 425-44I.

Weber, M. M., Matschiner, J. T. \& Peck, H. D., Jun. (1970). Menaquinone-6 in the strict anaerobes Desulfovibrio vulgaris and Desulfovibrio gigas. Biochemical and Biophysical Research Communications 38, 197-204. 